\title{
Pelarspovirus, a proposed new genus in the family Tombusviridae
}

\author{
Kay Scheets ${ }^{1} \cdot$ Ramon Jordan $^{3} \cdot$ K. Andrew White ${ }^{4}$ Carmen Hernández ${ }^{2}(1)$
}

Received: 27 March 2015/Accepted: 13 June 2015/Published online: 7 July 2015

(C) Springer-Verlag Wien 2015

\begin{abstract}
Currently, the family Tombusviridae encompasses thirteen viral genera that contain single-stranded, positive-sense RNA genomes and isometric virions; the exception being the genus Umbravirus, whose members do not encode a coat protein (CP). A new genus, tentatively named Pelarspovirus, is proposed to be added to this family and would include five members, with Pelargonium line pattern virus recommended as the type species. Viruses assigned to this proposed genus have monopartite
\end{abstract}

NOTE: The taxonomic changes suggested here have not been endorsed by the ICTV Executive Committee, may differ from any new taxonomy that is ultimately approved by the ICTV, and are presented for discussion only but have no official standing. Three proposals (2013.010a,bP.A.v2.Umbravirus_move,

2014.008aP.A.v3.Tombusviridae_sp and

2014.006aP.A.v2.Tombusviridae_4sp) cited in this article have been recently ratified by ICTV members and have been incorporated into the 2014 taxonomy (http://ictvonline.org/virusTaxonomy.asp). The initial submission for 2014.006aP.A.v2.Tombusviridae_4sp included the creation of a new genus Pelarspovirus. The ICTV Executive Committee (EC) did not support the creation of the genus since the newly proposed genus was not clearly delineated from all carmoviruses. The EC suggested the 2013 taxonomy for the family Tombusviridae may need to be revised, particularly noting the lack of monophylogeny for carmoviruses. In 2015, the Tombusviridae Study Group will be submitting a proposal to divide genus Carmovirus into three genera as shown in Figure 3a. This article is related to a taxonomic proposal planned for submission to the ICTV in 2015 and includes additional information not submitted to ICTV in 2014.

Kay Scheets

kay.scheets@okstate.edu

$\triangle$ Carmen Hernández

cahernan@ibmcp.upv.es

1 Department of Botany, 301 Physical Sciences, Oklahoma State University, Stillwater, OK 74078-3013, USA genomes encoding five open reading frames (ORFs) that include two $5^{\prime}$-proximal replication proteins, two centrally located movement proteins (MP1 and MP2) and a $3^{\prime}$ proximal CP that, at least for pelargonium line pattern virus (PLPV), has been shown to act also as suppressor of RNA silencing. Distinguishing characteristics of these viruses include i) production of a single, tricistronic subgenomic RNA for expression of MP and CP genes, ii) presence of a non-AUG start codon (CUG or GUG) initiating the MP2 ORF, iii) absence of AUG codons in any frame between the AUG initiation codons of MP1 and CP genes, and iv) sequence-based phylogenetic clustering of all encoded proteins in separate clades from those of other family members.

\section{Introduction}

The family Tombusviridae encompasses a broad range of soil-borne viruses characterized by icosahedral virions of about $30 \mathrm{~nm}$ in diameter and relatively small singlestranded positive-sense RNA genomes (average of $\sim 4,000 \mathrm{nt}$ ). To date, 71 species within the family whose members infect either dicotyledonous or monocotyledonous plants, have been formally recognized by the International Committee on Taxonomy of Viruses (ICTV) (http://ictvonline.org/virusTaxonomy.asp). Currently, the

2 Instituto de Biología Molecular y Celular de Plantas, Consejo Superior de Investigaciones Científicas-Universidad Politécnica de Valencia, Ciudad Politécnica de la Innovación, Ed. 8E. Camino de Vera s/n, 46022 Valencia, Spain 
family Tombusviridae includes thirteen genera; twelve of which contain viruses with single-stranded, positive-sense RNA genomes encoding coat proteins (CPs) for isometric virions, and genus Umbravirus, whose members lack a $\mathrm{CP}$ open reading frame (ORF) and are encapsidated by the CPs of their respective "helper" virus (30). The other twelve official genera are Tombusvirus, Carmovirus, Aureusvirus, Avenavirus, Machlomovirus, Alphanecrovirus, Betanecrovirus, Panicovirus, Dianthovirus, Gallantivirus, Macanavirus and Zeavirus [1, 29].

Genomes of viruses belonging to the family Tombusviridae are nonsegmented, with the exception of those belonging to the genus Dianthovirus, which are bisegmented. Tombusvirid genomes are neither $5^{\prime}$-capped nor $3^{\prime}$ polyadenylated and harbour from four to seven genes encoding proteins that minimally serve the basic functions of replication, movement and, with the exception of members of the genus Umbravirus, encapsidation. Virally encoded suppressors of RNA silencing (VSRs) have also been identified in members of some genera and vary in terms of structure and function [4]. To assist replication, all tombusvirids produce an essential accessory protein and an RNA-dependent RNA polymerase (RdRp). One, two, or three virally encoded movement proteins (MPs) mediate virus transport, and a single type of coat protein $(\mathrm{CP})$ is involved in virion formation. Virions have either a bumpy or a smooth appearance in electron micrographs, depending on the presence or absence, respectively, of a C-terminal protruding domain in the corresponding CP [29, 36]. General gene expression strategies include (i) translation of viral proteins facilitated by a $3^{\prime}$ cap-independent translational enhancer ( $\left.3^{\prime} \mathrm{CITE}\right)[29,35]$, (ii) synthesis of the RdRp as a $\mathrm{C}$-terminal extension of the accessory replication protein by either ribosomal readthrough or frameshifting, (iii) leaky scanning of ribosomes on bicistronic or polycistronic viral mRNAs, which allows expression of downstream ORFs, and (iv) transcription of subgenomic (sg) RNAs during infections to template translation of genes located internally and $3^{\prime}$-proximally in the genomic (g) RNA. The demarcation criteria for genera in the family Tombusviridae are "(A) structural criteria - spherical virions with either a smooth or granular appearance; (B) genomic criteria genome organization, number of genome segments, size of genome; and $(\mathrm{C})$ polymerase criteria - gene interrupted by a termination codon or a -1 ribosomal frameshifting element that is periodically read through" [29].

3 Floral and Nursery Plants Research Unit, U.S. National Arboretum, Agricultural Research Service, US Department of Agriculture, 10300 Baltimore Ave, Beltsville, MD 20705, USA

4 Department of Biology, York University, 4700 Keele St., Toronto, ON M3J-1P3, Canada
One of the recognized tombusvirid species that is not assigned to a genus is Pelargonium line pattern virus. The gene arrangement in the monopartite genome of pelargonium line pattern virus (PLPV), as well as the sequences of the encoded proteins, closely resembles that of carmoviruses [5, 14]. However, several traits distinguish PLPV, as well as four structurally and phylogenetically related viruses, from currently recognized carmoviruses and justify the proposal that this group should constitute a new genus within the family Tombusviridae, named $\mathrm{Pe}$ larspovirus [5, 15, 16].

\section{Proposed taxonomic structure of the genus}

Order: Unassigned

Family: Tombusviridae

Genus: Pelarspovirus

Type species: Pelargonium line pattern virus

Other proposed species within the genus:

Elderberry latent virus

Pelargonium chlorotic ring pattern virus

Pelargonium ringspot virus

Rosa rugosa leaf distortion virus

Complete sequences of each proposed member of the tentative genus Pelarspovirus have been determined (Table 1). A proposal for induction of Elderberry latent virus, Pelargonium chlorotic ring pattern virus, Pelargonium ringspot virus and Rosa rugosa leaf distortion virus as new species of family Tombusviridae has been recently approved and ratified by the Executive Committee of the ICTV [33]. We suggest the following species demarcation criteria in the new genus: $<75 \%$ amino acid sequence identity between RdRps and $<75 \%$ identity between CPs (Table 2). Rose yellow leaf virus (RYLV), a pathogen whose nearly complete nucleotide sequence has been determined recently [25], is considered an isolate of RrLDV (and not a member of a separate species) on the basis of the high sequence identity shared by their corresponding proteins $(90 \%, 95 \%, 82 \%$, and $86 \%$, respectively, for RdRp, CP, MP1 and MP2) [33].

The genus name "Pelarspovirus" comes from the underlined syllables of pelargonium ringspot virus, which was the first virus to be named and described among the five proposed members [13]. The proposed genus name was introduced prior to release of a full sequence of PelRSV or of any other member of the suggested genus [15]. Moreover, the term "pelarspovirus", with or without quotes and with or without the term "proposed" associated with it, can be found in published abstracts, papers and books, attesting to existing informal adoption of this genus name (1998-2015; some referenced here). 
Table 1 Properties of viruses in the proposed new genus Pelarspovirus, family Tombusviridae

\begin{tabular}{|c|c|c|c|c|c|c|c|}
\hline \multirow[t]{2}{*}{ Virus name } & \multirow{2}{*}{$\begin{array}{l}\text { GenBank accession } \\
\text { no. }{ }^{\text {a }}\end{array}$} & \multirow{2}{*}{$\begin{array}{l}\text { Genome length } \\
\text { (nt) }\end{array}$} & \multicolumn{5}{|c|}{ Coding regions (nt)/protein length (aa) } \\
\hline & & & p27 & $\mathrm{RdRp}$ & MP1 & $\mathrm{MP} 2^{\mathrm{b}}$ & $\mathrm{CP}$ \\
\hline PLPV & $\begin{array}{l}\text { AY613852 } \\
\text { EU835946 } \\
\text { EU849616 } \\
\text { AY038067 }\end{array}$ & 3,883 & $7-729 / 240$ & $7-2304 / 765$ & $2274-2465 / 63$ & $2371-2637 / 88$ & $2621-3637 / 338$ \\
\hline PelRSV & AY038068 & 3,865 & $15-725 / 236$ & $15-2303 / 762$ & $2273-2449 / 58$ & $2355-2606 / 83$ & $2593-3609 / 338$ \\
\hline PCRPV & AY038069 & 3,904 & $17-736 / 239$ & $17-2308 / 763$ & $2278-2463 / 62$ & $2369-2611 / 80$ & $2608-3621 / 337$ \\
\hline ELV & AY038066 & 3,892 & $43-762 / 239$ & $43-2331 / 762$ & $2301-2495 / 64$ & $2401-2649 / 82$ & $2639-3655 / 338$ \\
\hline RrLDV & $\begin{array}{l}\mathrm{KC} 166238 \\
\mathrm{KC} 166239\end{array}$ & 3,971 & $7-720 / 237$ & $7-2292 / 761$ & $2262-2444 / 60$ & $2350-2610 / 86$ & $2594-3613 / 339$ \\
\hline
\end{tabular}

${ }^{a}$ Full-length genome sequences reported to GenBank. The accession number of the quasi-full-length genome sequence of the previously designated RYLV (KC166239; [25]) is included as an isolate of RrLDV. PLPV isolate with accession no. AY038067 has a 5'-UTR that is one nucleotide shorter than those of the other isolates

${ }^{\mathrm{b}}$ Beginning with a non-AUG start codon

The selected type species, Pelargonium line pattern virus, was the first species in the proposed genus to be recognized by ICTV as an unassigned species in the family Tombusviridae. Moreover, the complete PLPV genome was the first to be made available, and this virus is currently the best characterized among the tentative members of this proposed genus. To date, work performed on PLPV at the molecular level includes (i) sgRNA mapping [5], (ii) generation of infectious cDNA clones under the control of the T7 RNA polymerase promoter or $35 \mathrm{~S}$ cauliflower mosaic virus promoter [6], (iii) analyses of gene function and translational mechanisms [8], (iv) analyses of molecular variability [7], and (v) identification of the VSR and its molecular interactions [26]. Though limited, data on the incidence of PLPV in cultivated geraniums in Spain have been also obtained [2].

\section{Biological properties}

No vector is known for any of the proposed members of the genus and transmission mainly occurs through propagating material. Natural infections with PLPV, pelargonium chlorotic ring pattern virus (PCRPV) and pelargonium ringspot virus (PelRSV) are restricted to Pelargonium spp.; however, despite this overlap in host range, the estimation of their RdRp (55-70\%; Table 2) and CP (43-71\%; Table 2) identities clearly indicates that these viruses belong to separate species. PLPV and PCRPV were originally isolated from $P$. zonale plants showing line pattern symptoms and chlorotic spots/ringspots, line pattern and vein banding, respectively, whereas PelRSV was originally isolated from $P$. peltatum exhibiting ringspot symptoms $[13,20,37$, and references therein]. Elderberry latent virus
Table 2 Percentages of amino acid sequence identity between the proteins of proposed pelarspoviruses and those of carmoviruses

\begin{tabular}{|c|c|c|c|c|c|}
\hline & PCRPV & PelRSV & PLPV & RrLDV & Carmoviruses \\
\hline & $\mathrm{RdRp}$ & & & & \\
\hline ELV & 55 & 70 & 57 & 58 & $37-43$ \\
\hline PCRPV & & 56 & 58 & 61 & $39-45$ \\
\hline PelRSV & & & 57 & 58 & $37-42$ \\
\hline PLPV & & & & 61 & $39-45$ \\
\hline \multirow[t]{2}{*}{ RrLDV } & & & & & $40-44$ \\
\hline & MP1 & & & & \\
\hline ELV & 48 & 69 & 53 & 47 & $15-35$ \\
\hline PCRPV & & 52 & 56 & 62 & $16-36$ \\
\hline PelRSV & & & 63 & 56 & $16-35$ \\
\hline PLPV & & & & 55 & $18-39$ \\
\hline \multirow[t]{2}{*}{ RrLDV } & & & & & $14-37$ \\
\hline & MP2 & & & & \\
\hline ELV & 41 & 69 & 53 & 52 & $11-29$ \\
\hline PCRPV & & 44 & 43 & 48 & $9-23$ \\
\hline PelRSV & & & 51 & 49 & $11-25$ \\
\hline PLPV & & & & 58 & $14-27$ \\
\hline \multirow[t]{2}{*}{ RrLDV } & & & & & $16-28$ \\
\hline & $\mathrm{CP}$ & & & & \\
\hline ELV & 44 & 71 & 50 & 44 & $11-29$ \\
\hline PCRPV & & 45 & 44 & 49 & $9-23$ \\
\hline PelRSV & & & 48 & 43 & $11-25$ \\
\hline PLPV & & & & 46 & $14-27$ \\
\hline RrLDV & & & & & $16-28$ \\
\hline
\end{tabular}

(ELV) was initially isolated from American elder (Sambucus canadensis) exhibiting line pattern symptoms, and no other plant species have been recorded as natural hosts of this virus [12]. RrLDV was originally found in Rosa 


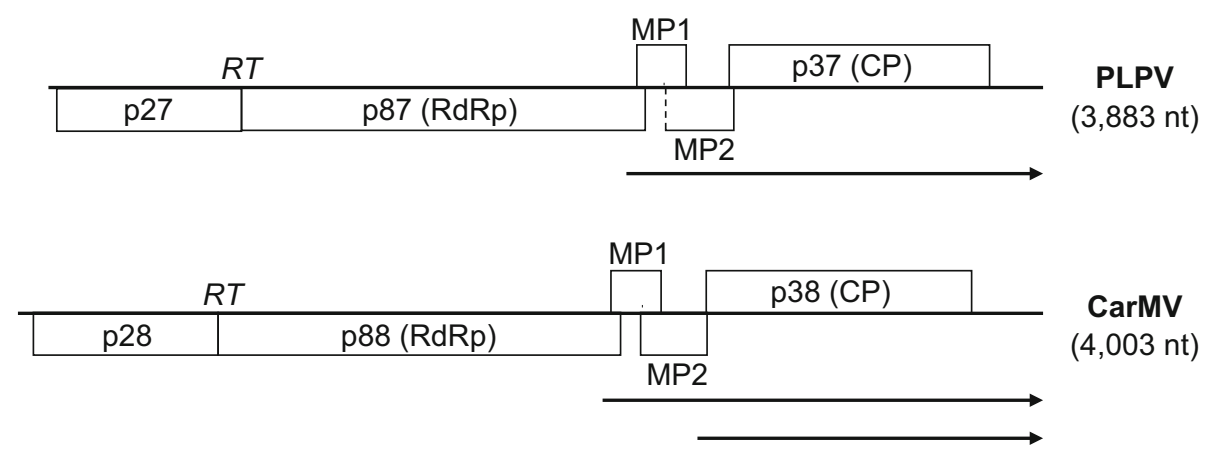

Fig. 1 Genome organization of the proposed type member pelargonium line pattern virus (PLPV) of genus Pelarspovirus compared to carnation mottle virus (CarMV), the type member of genus

rugosa cultivars showing stunting, leaf distortion and pale circular lines in early spring growth, and the RYLV isolate of RrLDV was found in Rosa spp. with blotchy yellow mosaic symptoms [24, 25]. Information on other potential natural hosts of either isolate of RrLDV is absent. Mechanical transmissibility has not been reported for RrLDV, but the remaining members of the proposed genus can be readily transmitted by mechanical sap inoculation to common experimental hosts such as Chenopodium quinoa, Nicotiana benthamiana or N. clevelandii. PLPV, PelRSV and ELV induce local chlorotic lesions in C. quinoa and establish symptomless systemic infections in $N$. benthamiana and N. clevelandii. PCRPV also induces local chlorotic lesions in $C$. quinoa, though systemic chlorotic lesions have been occasionally observed at high temperatures. Furthermore, PCRPV causes symptomless systemic infection in $N$. benthamiana and induces local chlorotic lesions and systemic mottle in $N$. clevelandii.

\section{Genomic organization and coding properties}

Full-length nucleotide sequences of all tentative members of the genus Pelarspovirus have been deposited in GenBank (Table 1). In the case of PLPV and RrLDV, complete or near-complete genome sequences of distinct isolates are available (Table 1). The viruses have a monopartite, ssRNA genome ranging in length between 3,865 (PelRSV) and 3,971 nt (RrLDV).

In silico analysis has allowed the identification of five ORFs in each viral genome (Fig. 1 and data not shown). In all cases, the 5'-proximal ORF, ORF1, encodes a protein of $\sim 27 \mathrm{kDa}(\mathrm{p} 27)$ that shows homology to auxiliary replication proteins of tombusvirids [5, 16, 24, 25], such as those of carmoviruses (Table 2). Each ORF1 begins with AUG in a favorable translation context (A or $G$ at positions -3 and +4 , with the exception of PCRPV ORF1, which has a $\mathrm{U}$ at position +4$)[18,21]$ and terminates at a UAG
Carmovirus. $R T$ indicates the readthrough stop codon punctuating the RdRp. Thin arrows under genomes indicate sgRNAs. The dashed line of PLPV MP2 indicates a noncanonical start codon (see Fig. 2)

codon. This amber codon is in all cases surrounded by an almost identical sequence (aaUAGggg/a) that is consistent with consensus motifs for type III readthrough elements [10]. Bypass of the stop codon allows expression of the inframe, downstream ORF and gives rise to a protein of 87 $\mathrm{kDa}(\mathrm{p} 87$ ) that contains the motifs characteristic of viral RdRps, including the highly conserved GDD box [17], as well as others specific to tombusvirid RdRps [11]. Two centrally located ORFs encode two small polypeptides that share significant sequence similarities with known MPs (Table 2). The theoretical molecular masses of those proteins range from 6.1 to $6.9 \mathrm{kDa}(\mathrm{MP} 1)$ and from 8.9 to 9.7 $\mathrm{kDa}$ (MP2). MP1 ORF starts in all proposed pelarspoviruses at an AUG in a poor translational context (a favorable $\mathrm{G}$ at position +4 but a pyrimidine at position -3 ), which may allow leaky scanning of ribosomes past this initiation site to occur. Strikingly, the MP2 ORFs initiate with a noncanonical start codon (GUG or CUG) instead of a conventional AUG (Fig. 2). The 3'-proximal ORF initiates with an AUG in an optimal translation context and encodes a CP of about $37 \mathrm{kDa}$ (p37). Like the CPs of viruses belonging to the genera Tombusvirus, Carmovirus, Aureusvirus, Avenavirus, Dianthovirus, Gallantivirus, and Macanavirus, the CPs of members of the proposed genus Pelarspovirus harbour a protruding domain that gives virions a granular appearance when examined by electron microscopy [19].

The genomes of the proposed pelarspoviruses are rather compact with no intergenic regions (Fig. 1 and Table 1). The ORFs are flanked by untranslated regions (UTRs) of variable lengths. The 5' UTRs are short (14-43 nt) for PelRSV, PCRPV and ELV, or very short as found for PLPV and RrLDV, with just 5-6 nt (Table 1). The 3' UTRs range from 237 (ELV) to $358 \mathrm{nt}$ (RrLDV) and show little sequence identity between members of different species $(<45 \%)$. However, in silico analyses of the $3^{\prime}$ UTRs indicate that they may fold into several stem-loop structures [7, and data not shown] that likely act as signals for 


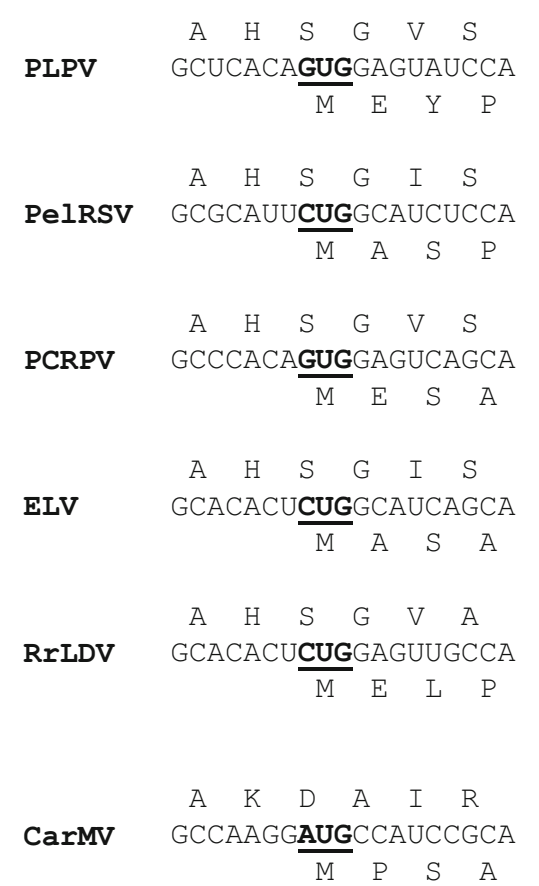

Fig. 2 Contexts for MP2 noncanonical start codons (bold and underlined) for proposed members of genus Pelarspovirus (PLPV, pelargonium ringspot virus [PelRSV], pelargonium chlorotic ring pattern virus [PCRPV], elderberry latent virus [ELV], and Rosa rugosa leaf distortion virus [RrLDV]) compared to that of CarMV MP2. MP1 and MP2 amino acid sequences are located above and below the RNA sequences, respectively

viral replication and/or translation, in line with what has been reported for other tombusvirids [9, 27, 35]. Nevertheless, experimental evidence for the functionality of the predicted structural motifs in the $3^{\prime}$ UTR remains to be obtained.

At the genus level, proteins encoded by pelarspoviruses have the highest similarity scores with the equivalent proteins of carmoviruses (Table 2). However, in contrast to carmoviruses, which produce two sgRNAs to express genes in the $3^{\prime}$ half of their genomes, pelarspoviruses are known (PLPV, ELV, PCRPV, PelRSV) [5, 14-16] or predicted (RrLDV) [24] to generate only one sgRNA (Fig. 1), similar to that reported for panicoviruses [39] and maize chlorotic mottle virus, the only member of the genus Machlomovirus [31]. The synthesis of a single sgRNA was initially suggested by the presence of two virus-specific dsRNA species in pelarspovirus-infected plants, compared to the expected three dsRNA species found in carmovirus infections [14, 16, 20].

Study of gene functions in PLPV confirmed the involvement of p27 and p87 in replication, of MP1 (p6) and MP2 (p9.7) in viral movement, and of p37 in encapsidation [8]. A recent report also revealed that PLPV p37, besides acting as a CP, also functions as a VSR [26], paralleling results obtained with several carmoviruses [22, 23, 28].
Analyses of translation strategies corroborated that PLPV p27 and p87 are expressed from the gRNA (p87 as a readthrough product of $\mathrm{p} 27$ ) and that the unique sgRNA detected in infected tissue serves as mRNA for expression of the MP1, MP2 and p37 genes [8]. Translation of all three genes from the sgRNA is accomplished through leakyscanning processes that are favoured by the suboptimal translational context of the initiating AUG of the MP1 gene, the noncanonical start codon (GUG) of MP2 gene, and the lack of an AUG codon between the MP1 AUG and CP AUG. These genomic traits are shared by the remaining proposed pelarspoviruses, which provides good support for the generality of the translation strategy.

In an initial examination of the PLPV genome through in silico approaches, the presence of a p13 ORF overlapping the readthrough region of RdRp, a p6 ORF with no AUG initiation codon in the central region of the genome, and the production of a $12-\mathrm{kDa}$ protein via a -1 frameshift of MP1 were predicted [5]. However, subsequent work on PLPV translation schemes and gene functions indicated that the predicted p13 and p6 ORFs are non-functional and that no MP1 fusion protein is produced [8]. Similar MP1 fusions have been hypothesized for other proposed members of genus Pelarspovirus [16, 24, 25], but in light of the results with PLPV, they are very unlikely to be synthesized. For RrLDV, some small ORFs were noted in different positions of the genome [24, 25]. However, the encoded proteins have no significant similarities to known viral (or non-viral) protein sequences. Moreover, they are not conserved between the two characterized isolates of the virus, which poses serious doubts regarding their biological significance.

\section{Phylogenetic relationships}

Since the RdRps of umbraviruses form a separate clade from all CP-coding tombusvirids [30], they were omitted from phylogenetic analysis for this report. PLPV and other proposed pelarspoviruses are phylogenetically closer to each other than to members of other genera of the family Tombusviridae (Fig. 3), although the similarity of their genome organization to viruses currently identified as carmoviruses is apparent (Fig. 1). The Tombusviridae Study Group has found that when comparing phylogenetic analyses of all viral proteins, the RdRp tree most consistently groups viruses within genera as defined by the demarcation criteria [29]. Therefore RdRp phylogenetic trees are used to delineate genera for viruses such as alphanecroviruses and betanecroviruses that are not separated into monophyletic lineages using the three criteria described above. Our data support the division of carmoviruses into three genera. Nine of ten RdRp 
a

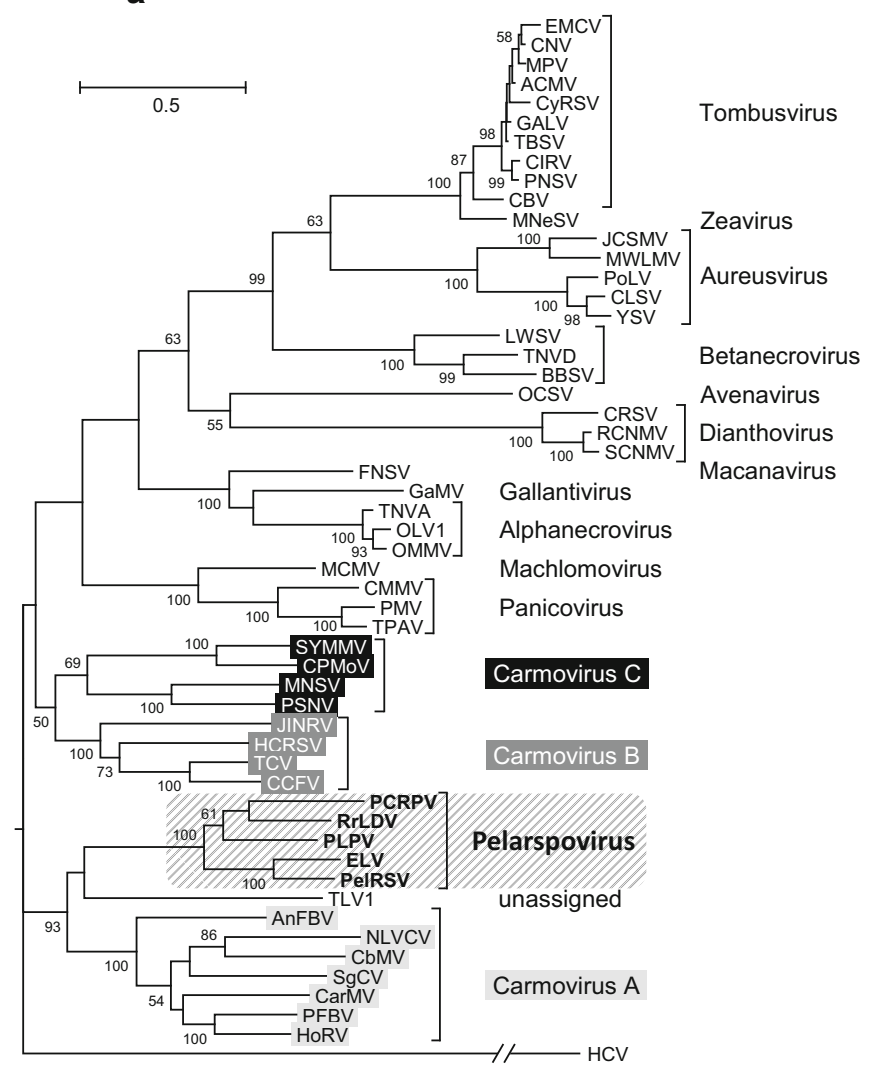

b

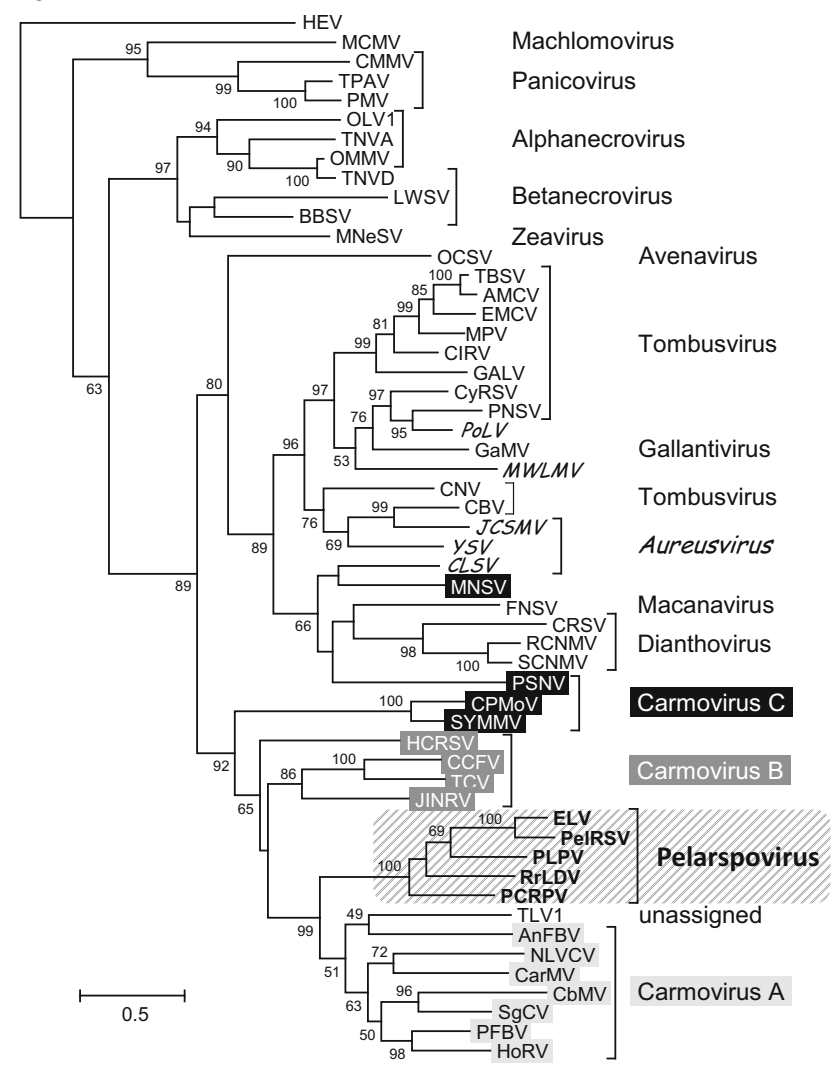

C

MP1

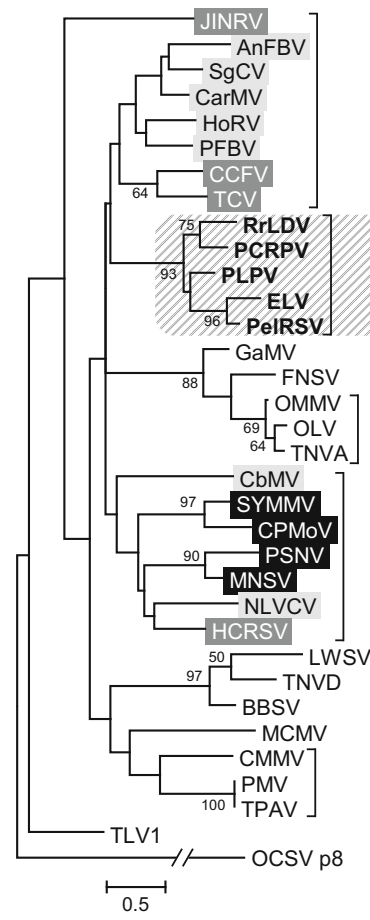

$\underline{\text { Carmovirus }}$

Pelarspovirus

Gallantivirus

Macanavirus

Alphanecrovirus

Carmovirus

Betanecrovirus

Machlomovirus

Panicovirus

unassigned Avenavirus
MP2

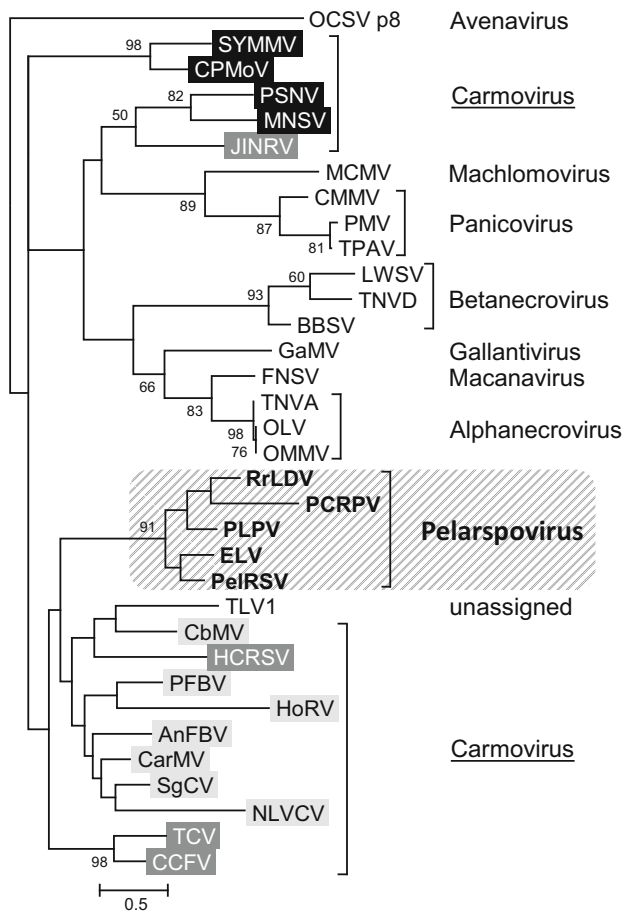


4Fig. 3 Phylogenetic trees of the RdRps of CP-encoding tombusvirids (a), CPs (b) and two small movement proteins, MP1 and MP2 (c). Alignments were made using ClustalOmega or MUSCLE, and trees were generated by the maximum-likelihood (ML) or neighbor-joining (N-J) method using two or three gap treatments: complete deletion of gaps or missing data, deletion of sites with $<50 \%$ coverage, or pairwise deletion. ClustalOmega ML trees with $50 \%$ coverage are shown, and there were a total of 745 (a), 356 (b), and 65 or 83 (c) positions in the final datasets. Numbers at branches show the percentage bootstrap support (if $>50 \%$ ) for 1000 replicates. The scales indicate JTT amino acid distances. N-J trees showed a similar topology, with the exception of those performed with MP2 sequences, which exhibited some differences but had all proposed pelarspoviruses clustering in a branch separate from other tombusvirids (not shown). Evolutionary analyses were conducted in MEGA5 [38]. Virus isolate names, acronyms and GenBank/Refseq accession numbers are as follows: angelonia flower break virus (AnFBV; DQ219415), artichoke mottled crinkle virus (AMCV; X62493), beet black scorch virus (BBSV; AF452884), calibrachoa mottle virus (CbMV; GQ244431), cardamine chlorotic fleck virus (CCFV; L16015), carnation Italian ringspot virus (CIRV; X85215), (CarMV; X02986), carnation ringspot virus (CRSV; L18870), cocksfoot mild mosaic virus (CMMV; EU081018), cowpea mottle virus (CPMV; U20976), cucumber Bulgarian virus (CBV; AY163842), cucumber leaf spot virus (CLSV; EU127904), cucumber necrosis virus (CNV; M25270), cymbidium ringspot virus (CyRSV; X15511), eggplant mottled crinkle virus (EMCV; JQ864181), elderberry latent virus (ELV; AY038066), furcraea necrotic streak virus (FNSV; FJ768020), galinsoga mosaic virus (GaMV; Y13463), grapevine Algerian latent virus (GALV; AY830918), hibiscus chlorotic ringspot virus (HCRSV; X86448), honeysuckle ringspot virus (HoRSV; HQ677625), Japanese iris necrotic ring virus (JINRV; D86123), johnsongrass chlorotic stripe mosaic virus (JCSMV; AJ557804), leek white stripe virus (LWSV; X94560), maize chlorotic mottle virus (MCMV; X14736), maize necrotic streak virus (MNeSV; AF266518), maize white line mosaic virus (MWLMV; EF589670), melon necrotic spot virus (MNSV; M29671), Moroccan pepper virus (MPV; JX197071), Nootka lupine vein clearing virus (NLVCV; EF207438), oat chlorotic stunt virus (OCSV; X83964), olive latent virus 1 (OLV1, X85989), olive mild mosaic virus (OMMV; AY616760), panicum mosaic virus (PMV; U55002), pea stem necrosis virus (PSNV; AB086951), (PCRPV; AY038069), (PFBV; AJ514833), (PLPV; AY613852), pelargonium necrotic spot virus (PNSV; AJ607402), (PelRSV; AY038068), pothos latent virus (PoLV; X87115), red clover necrotic mosaic virus (RCNMV; J04357), (RrLDV; KC166238), saguaro cactus virus ( $\mathrm{SgCV}$; U72332), soybean yellow mottle mosaic virus (SYMMV; FJ457015), sweet clover necrotic mosaic virus (SCNMV; L07884), thin paspalum asymptomatic virus (TPAV; JX848617), tobacco necrosis virus A (TNVA; M33002), tobacco necrosis virus D (TNVD; U62546), tomato bushy stunt virus (TBSV; M21958), trailing lespedeza virus 1 (TLV1; HM640935), turnip crinkle virus (TCV; M22445), yam spherical virus (YSV; KF482072). Hepatitis C virus (HCV) RdRp (ADC54804.1) and hepatitis E virus (HEV) CP (AAA45727.1) provided outgroups for trees in panels a and b, respectively, while OCSV p8 was used as outgroup for both MP trees in panel $\mathrm{c}$

phylogenetic analyses (two alignment methods with two statistical approaches using two or three treatments of gaps and missing data) generated trees with identical monophyletic clustering of genus members when carmoviruses were divided into three genera (Fig. 3a and data not shown). Unlike members of several tombusvirid genera, independent alignments of the RdRp, MP1, MP2 and CP sequences consistently cluster the proposed pelarspoviruses together, supporting the conclusion that they should be included in a distinct genus. The phylogenetic separation is further supported by key transcription/translation-related traits that include the production of a single $\operatorname{sgRNA}$, the presence of a non-AUG triplet as the start codon of the MP2 gene, and the absence of AUG codons in any frame between the AUG initiation codons of the MP1 and CP genes. These traits mark a clear distinction from their closest relatives in the family, the current members of the genus Carmovirus. The different patterns of phylogenetic branching in the four trees of Fig. 3 could be explained in part by different rates of evolution between the distinct proteins of these viruses, though the possibility of some shuffling of sequences through recombination cannot be ruled out.

Recently, methods for assessing the relatedness of viruses based on whole genome sequence comparisons have been proposed that can help parse viruses at the family, genus, and isolate level. The Pairwise Sequence Comparison (PASC; http://www.ncbi.nlm.nih.gov/sutils/ pasc/viridty.cgi) classification tool was set up at the National Center for Biotechnology Information to provide a uniform analysis method for viral genomes [3]. PASC analysis of members of the Tombusviridae separated the majority of the viruses into their current taxonomic groups, with the proposed pelarspoviruses as a new genus (data not shown). Although the Tombusviridae Study Group has not defined family, genus, and species demarcation criteria by this method, we consider it additional support for the creation of the proposed genus Pelarspovirus. Remarkably, the same analysis indicated that viruses in GenBank identified by the submitters or the ICTV as carmoviruses may represent nine unique genera (data not shown), further highlighting the need to revise the current criteria for inclusion in the genus Carmovirus.

A virus characterized through a metagenomic survey approach, trailing lespedeza virus 1 (TLV1) [32], was identified in the phylogenetic trees as most closely related to pelarspoviruses. The genome structure of TLV1 parallels that of carmoviruses and pelarspoviruses, resembling the latter in the use of a noncanonical CUG start codon for MP2 ORF and the absence of AUG codons between the predicted MP1 and CP start codons. TLV1 has recently been ratified as an unassigned tombusvirid by the ICTV [34]; however, the phylogenetic positions of its encoded proteins (Fig. 3) suggest that it is likely to be a member of a currently unidentified sister clade, and PASC analysis supports this notion (data not shown).

To conclude, we consider that there is sufficient molecular and phylogenetic support for the creation of the new genus Pelarspovirus in family Tombusviridae. 
Acknowledgments Research at the C. H. laboratory was supported by grant BFU2012-36095 from the Ministerio de Economía y Competitividad (MINECO, Spain). Pelargonium virus research at the R. J. laboratory was supported through funding from Binational Agricultural Research and Development Fund Project No. US-2336-93R and United States Department of Agriculture, Agricultural Research Service, Research Project No. 8020-22000-032-00D (and its predecessors). Research in the laboratory of K.A.W. is supported by the Natural Sciences and Engineering Research Council of Canada. Research in the K.S. laboratory on tombusvirid phylogeny was supported by National Science Foundation EPSCoR grant EPS-0447262.

\section{Compliance with ethical standards}

Conflict of interest K Scheets (2011-present) and K.A. White (2013-present) are members of the International Committee on Taxonomy of Viruses (ICTV) Tombusviridae Study Group. K. Scheets became chair in August 2014.

\section{References}

1. Adams MJ, King AMQ, Carstens EB (2013) Ratification vote on taxonomic proposals to the International Committee on Taxonomy of Viruses (2013). Arch Virol 158:2023-2030

2. Alonso M, Borja M (2005) High incidence of pelargonium line pattern virus infecting asymptomatic Pelargonium spp. in Spain. Eur J Plant Pathol 112:95-100

3. Bao Y, Chetvernin V, Tatusova T (2014) Improvements to pairwise sequence comparison (PASC): a genome-based web tool for virus classification. Arch Virol 159:3293-3304

4. Burgyan J, Havelda Z (2011) Viral suppressors of RNA silencing. Trends Plant Sci 16:265-272

5. Castaño A, Hernández C (2005) Complete nucleotide sequence and genome organization of pelargonium line pattern virus and its relationship with the family Tombusviridae. Arch Virol 150:949-965

6. Castaño A, Hernández C (2007) Biological activity of transcripts from cDNA of pelargonium line pattern virus. Acta Virol 51:271-274

7. Castaño A, Ruiz L, Elena SF, Hernández C (2011) Population differentiation and selective constraints in pelargonium line pattern virus. Virus Res 155:274-282

8. Castaño A, Ruiz L, Hernández C (2009) Insights into the translational regulation of biologically active open reading frames of pelargonium line pattern virus. Virology 386:417-426

9. Fabian MR, Na H, Ray D, White KA (2003) 3'-Terminal RNA secondary structures are important for accumulation of tomato bushy stunt virus DI RNAs. Virology 313:567-580

10. Firth AE, Brierley I (2012) Non-canonical translation in RNA viruses. J Gen Virol 93:1385-1409

11. Gunawardene CD, Jaluba K, White KA (2015) Conserved motifs in a tombusvirus polymerase modulate genome replication, subgenomic transcription, and amplification of defective interfering RNAs. J Virol 89:3236-3246

12. Jones AT, McGavin WJ, Brunt AA, Philipps S (2000) Elderberry latent virus: its relationship to pelargonium ringspot virus and its identification as a distinct member of the genus Carmovirus. Ann App Biol 136:147-152

13. Hollings M (1957) Pelargonium ring spot. Plant Pathology 6:17-18

14. Kinard GR, Hurtt SS, Jordan RL (1996) Partial characterization of pelargonium line pattern and pelargonium ringspot viruses. Acta Hortic 432:48-155
15. Kinard GR, Jordan RL (1998) Genome organization of pelargonium ringspot and elderberry latent viruses. Phytopathology 88:S48

16. Kinard GR, Jordan R (2002) Genome organization of pelargonium chlorotic ring pattern virus: further implications for Tombusviridae taxonomy. Acta Hortic 568:17-27

17. Koonin EV, Dolja VV (1993) Evolution and taxonomy of positive-strand RNA viruses: implications of comparative analysis of amino acid sequences. Crit Rev Biochem Mol Biol 28:375-430

18. Kozak M (1986) Point mutations define a sequence flanking the AUG initiator codon that modulates translation by eukaryotic ribosomes. Cell 44:283-292

19. Lesemann DE, Adam G (1994) Electron microscopical and serological studies on four isometrical pelargonium viruses. Acta Hortic 377:41-54

20. Lisa V, Vaira AM, Dellavalle G, Masenga V, Milne RG (1996) Viruses of pelargonium in Italy. Acta Hortic 432:108-117

21. Lukaszewicz M, Feuermann M, Jérouville B, Stas A, Boutry M (2000) In vivo evaluation of the context sequence of the translation initiation codon in plants. Plant Sci 154:89-98

22. Martínez-Turiño $S$, Hernández $C$ (2009) Inhibition of RNA silencing by the coat protein of pelargonium flower break virus: distinctions from closely related suppressors. J Gen Virol 90:519-525

23. Meng C, Chen J, Peng J, Wong SM (2006) Host-induced avirulence of hibiscus chlorotic ringspot virus mutant correlates with reduced gene-silencing suppression activity. J Gen Virol $87: 451-459$

24. Mollov D, Lockhart B, Zlesak DC (2013) Complete nucleotide sequence of Rosa rugosa leaf distortion virus, a new member of the family Tombusviridae. Arch Virol 158:2617-2620

25. Mollov D, Lockhart B, Zlesak DC (2014) Complete nucleotide sequence of rose yellow leaf virus, a new member of the family Tombusviridae. Arch Virol 159:2795-2798

26. Pérez-Cañamás M, Hernández C (2015) Key importance of small RNA binding for the activity of a glycine/tryptophan (GW) motifcontaining viral suppressor of RNA silencing. J Biol Chem 290:3106-3120

27. Pogany J, Fabian MR, White KA, Nagy PD (2003) A replication silencer element in a plus-strand RNA virus. EMBO J 22:5602-5611

28. Qu F, Ren T, Morris TJ (2003) The coat protein of turnip crinkle virus suppresses posttranscriptional gene silencing at an early initiation step. J Virol 77:511-522

29. Rochon D, Rubino L, Russo M, Martelli GP, Lommel S (2012) Tombusviridae. In: King AMQ, Adams MJ, Carstens EB, Lefkowitz EJ (eds) Virus taxonomy-Ninth Report of the International Committee on Taxonomy of Viruses. Academic Press, London, pp 1111-1138

30. Rochon D, Scheets K, White A, Martelli G, Rubino L (2014) ICTV taxonomic proposal 2013.010a,bP.A.v2.Umbravirus_move. Move genus Umbravirus into family Tombusviridae. http:// www.ictvonline.org/proposals-14/2013.010a,bP.A.v2.Umbravirus_ move.pdf

31. Scheets K (2000) Maize chlorotic mottle machlomovirus expresses its coat protein from a $1.47-\mathrm{kb}$ subgenomic RNA and makes a 0.34-kb subgenomic RNA. Virology 267:90-101

32. Scheets K, Blinkova O, Melcher U, Palmer MW, Wiley GB, Ding T, Roe BA (2011) Detection of members of the Tombusviridae in the Tallgrass Prairie Preserve, Osage County, Oklahoma, USA. Virus Res 160:256-263

33. Scheets K, Hernández C, Jordan R, White A (2014) ICTV taxonomic proposal 2014.006aP.A.v2.Tombusviridae_4sp. Create 4 new species unassigned in the family Tombusviridae. http://www. ictvonline.org/proposals-14/2014.006aP.A.v2.Tombusviridae_4sp. pdf 
34. Scheets K, Melcher U (2014) ICTV taxonomic proposal 2014.008aP.A.v3.Tombusviridae_sp. Create 1 new species unassigned in the family Tombusviridae. http://www.ictvonline. org/proposals-14/2014.008aP.A.v3.Tombusviridae_sp.pdf

35. Simon AE, Miller WA (2013) 3' Cap-independent translation enhancers of plant viruses. Annu Rev Microbiol 67:21-42

36. Sit TL, Lommel SA (2010) Tombusviridae. In: Encyclopedia of life sciences. Nature-Scientific American Publishing Group, London, UK. http://www.els.net

37. Stone OM (1980) Nine viruses isolated from pelargonium in the United Kingdom. Acta Hortic 110:177-182
38. Tamura K, Peterson D, Peterson N, Stecher G, Nei M, Kumar S (2011) MEGA5: molecular evolutionary genetics analysis using maximum likelihood, evolutionary distance, and maximum parsimony methods. Mol Biol Evol 28:2731-2739

39. Turina M, Desvoyes B, Scholthof KBG (2000) A gene cluster encoded by panicum mosaic virus is associated with virus movement. Virology 266:120-128 